\title{
Coconut Farming Industry in Dingalan, Aurora: Practices and Challenges
}

\author{
Helen Grace P. Datang ${ }^{1}$, Julie Mier E. Lomanog ${ }^{2}$, Felipe E. Balaria ${ }^{3}$ \\ Nueva Ecija University of Science and Technology, Philippines \\ 1helengrace 1127@yahoo.com.ph; ${ }^{2}$ julie mier 9259@yahoo.com; ${ }^{3}$ pbalaria@yaho.com
}

\begin{abstract}
This study attempted to describe the status of coconut farming industry practices and challenges in Dingalan, Aurora. Using Descriptive research design with 50 purposively chosen coconut farmers as respondents, the study revealed that the coconut farming industry in the subject town was in need of improvement in terms of farming practices. It also needed assistance to addressing the challenges that included low yield and lack of strong political assistance. Two from among the recommendations were to establish an extension activity focused on farmers ' training and capability building and to strengthen political will in promoting marketing and farming practices in the town.
\end{abstract}

Keywords- Coconut farming industry, coconut farming practices, industry challenges.

\section{INTRODUCTION}

"The coconut is a very useful plant with a wide range of products being sourced from it. Coconut products are used to make everything from clothing to animal feed to beauty creams [1]."

Coconut palm is grown in over 80 countries worldwide and excels in tropics, like India, Philippines and Indonesia [2].

Among the coconut producing countries in the world, "India has made unprecedented progress in coconut cultivation from mid 2014 to 2018 and now it has become the leading country in coconut production and productivity. Productivity increased to 11516 fruits per hectare in 2017 18 as compared to 10122 in 2013-14. Between 2014 and 2018, 13,117 hectare was brought under new plantation as compared to 9,561 hectare during 2010-2014."[3]. This has given India a huge income and consequently provided jobs to most of their unemployed youths.

Aside from India, coconut farming is also a profitable industry in the Philippines. With 68 out of 81 coconut growing provinces in the country, coconut exports earn more than a billion dollars for the country every year [4].
More or less, 3.5 million hectares of the country is currently planted with about 339 million nutbearing trees. Each tree bears an average of 46 nuts per year or an average of 13.8 million of nuts annually. At first glance, the figure may appear large, but in comparison with other coconut growing countries, our country's coconut yield is way behind that of India, Mexico and Brazil where the average nut yield per tree were 250, 300 and 400 respectively.

According to author in [4], "coconut farmers in the Philippines are more or less 3.4 million; but with the current situation of coconut industry in the country, it can be deduced that these coconut farmers must be living below poverty line. It is ironic because coconut farming has big potential, if only problems related to it could be addressed."

Problems in coconut farming include low yield per tree due to low genetic quality, absence of fertilizer; and limited replacement of aged trees. The unorganized supply chain also adds up to the misfortune of the coconut farmers, because it tends to disperse small holdings resulting to high logistics cost due to small production lots and high transport [5].

There are other issues that confront the coconut industry. These include the following: lack of a serious development program for the industry; resource allocation criteria, which is biased toward rice; institutional issues with the PCA implementing mostly under-funded, short duration programs; implementation of programs with limited involvement of LGUs, the private sector, the civil society, and the academe; and the lack of civil society engagement, particularly in analyzing and settling the issues, which can be addressed by a strong political will, except for low yield which can be addressed at the farm level. The average yield of 46 nuts per tree per year may be increased by using hybrid variety and by application of good agricultural practices. On the other side, an organized system of marketing can also help cut expenses and thus boost profit.

With the way things are in the coconut farming industry, it is believed that a study could help. That is why 
the proponents ventured on this research, taking the case of Dingalan, Aurora in focus.

According to the Philippine Statistics Authority, Dingalan has a land area of 304.55 square kilometers constituting $9.68 \%$ of the 3,147.32-square-kilometre total area of Aurora. Dingalan's total land area comprises of 24,706 hectares of forestland and 15,972.15 hectares of alienable and disposable land which includes 2,981 hectares of farmland and 315.44 hectares of built up areas. The $25 \%$ or 7,714.51 hectares of the municipality is considered as agricultural land and 55.65 hectares are used for coconut intercropping [6].

Next to fishing, rice farming and forestry, coconut farming has become a major source of livelihood in Dingalan, Aurora. Coconut farming is very conducive in the locality because of its type IV climate and the salty sea breeze which is considered beneficial to coconut growth. However, the actual status of the industry in the municipality is undetermined due to lack of baseline data from the Municipal Agriculture Office (MAO) and from the Philippine Coconut Authority [7].

Generally, the study sought to determine the status of coconut farming in Dingalan, Aurora. It specifically aimed to:

1. Describe the status of coconut farming industry in Dingalan in terms of:

1.1 Size of coconut farm by farmer

1.2 Number of trees grown

1.3 Annual coconut yield per tree

2. Describe the coconut farming practices in Dingalan in terms of:

2.1 Insect pest and use of pesticides

2.2 Coconut diseases and use of chemicals

2.3 Fertilizer management

3. Describe the marketing practices in the coconut industry of Dingalan.

4. Describe the coconut industry in terms of financial aspect.

Table.1: Coconut Farming in Dingalan

\begin{tabular}{|l|c|c|}
\hline Size of coconut plantation by farmer (hectare) & Frequency & Percentage \\
\hline 1.0 to 1.5 hectares & 28 & $56 \%$ \\
\hline 1.6 to 2.0 hectares & 6 & $12 \%$ \\
\hline 2.1 to 2.5 hectares & 4 & $8 \%$ \\
\hline 2.6 hectares and above & 12 & $24 \%$ \\
\hline Total & 1.68 & $100 \%$ \\
\hline Mean & & \\
\hline Number of Coconut Trees Grown by Entrepreneurial Classification & 6 & $12 \%$ \\
\hline Small Scale Coconut Farmer (10-50 trees) & 16 & $32 \%$ \\
\hline Medium Scale Coconut Farmer (51-149 trees) & 19 & $38 \%$ \\
\hline Large Scale Coconut Farmer (150-250 trees) & & 30 \\
\hline
\end{tabular}




\begin{tabular}{|l|c|c|}
\hline Extra Large Scale Coconut Farmer (above 250 trees) & 9 & $18 \%$ \\
\hline Total & 50 & $100 \%$ \\
\hline Annual Coconut Yield per Tree & & \\
\hline $31-60$ & 6 & $12 \%$ \\
\hline $61-90$ & 12 & $24 \%$ \\
\hline $91-120$ & 17 & $34 \%$ \\
\hline $121-150$ & 5 & $10 \%$ \\
\hline $151-180$ & 9 & $18 \%$ \\
\hline 181 and above & 1 & $2 \%$ \\
\hline Total & 50 & $100 \%$ \\
\hline Mean harvest per year & 107 & \\
\hline
\end{tabular}

\section{Land area planted with coconut}

It can be viewed from Table 1 that majority of the respondents comprising 28 or $56 \%$ have one (1) to 1.5 hectares of land planted to coconut. Second majority (12 or $24 \%$ ) have 2.6 hectares and above; followed by six (6) or $12 \%$ have 1.6 to 2.0 hectares and four (4) or $8 \%$ have 2.1 to 2.5 hectares coconut farm, respectively.

The average area of coconut farm per farmer is 1.68 hectares. This implies that the area planted to coconut is manageable for each farmer. With the size, the farmer may have ample time to attend to their crops and the management needed, considering that coconut trees do not need as much attention as the seasonal crops required. What the farmers probably need the most are the technical knowhow as regarding pest control and financing.

\section{Number of Trees Grown}

It can be gleaned from Table 1 that the number of coconut trees grown in Dingalan was described in accordance to their entrepreneurial classification or whether they could be considered small, medium large or extralarge.

The findings revealed that majority of them comprising 19 or $38 \%$ were classified as large scale with 150 to 250 trees grown in their farm; followed by 16 or $32 \%$ which is medium scale and thus maintains 51 to 149 trees. Only nine (9) or $18 \%$ and six (6) or $12 \%$ can be described as extra-large and growing more than 250 trees, and under small scale classification with 10-50 trees, respectively.

\section{Annual Coconut Yield}

Table 1 also shows that the average annual yield of coconut trees in Dingalan was 107, which was larger than the national average yield of 46 per tree per year. Majority of the respondents (17 or 34\%) claimed that they harvested 91-120 pieces per year; 12 or $24 \%$ claimed they harvested 61 to 90 ; and the rest were harvesting either 151 to 180 or even as few as 31 to 60 .

The findings indicated that there was still much room to improve coconut yield in the Dingalan to make it comparable with the yield in other Asian countries.

\section{Coconut farming practices in Dingalan}

The coconut farming practices in Dingalan were described in terms of insect and pest, and chemical/fertilizer management.

\section{Use of insecticides/pesticides}

The data shown in Table 2 revealed that rat was voted by 19 or $38 \%$ of the respondents as the pest most devastating to their crop; followed by coconut leaf beetle with 16 or $32 \%$ vote, and by rhinoceros beetle with 15 or $30 \%$ vote. Despite these identified pests, however, it was found out that only four (4) or $8 \%$ resorted to using pesticide, while a very big majority comprising 46 or $92 \%$ did not use any pesticide at all.

The findings implied that while there were presence of pests which may negatively affect production, the farmers barely employed preventive measures to control them. The coconut trees might be infested and yet the farmers would not use pesticides to avert them. It could be because of any or all of the following: farmers were not aware of the benefits of using pesticides; they did not have financial means to buy chemicals; or there were no pesticides available in Dingalan. One thing may be certain; if the practice continues, the coconut farms may have been seriously infested before the farmers knew it. 
Table.2: Summary Table for Insect/Pest and Use of Pesticides by Farmers

\begin{tabular}{|l|c|c|}
\hline Insect/ Pest & Frequency & Percentage \\
\hline Coconut leaf Beetle & 16 & $32 \%$ \\
\hline Rat & 19 & $38 \%$ \\
\hline Rhinoceros Beetle & 15 & $30 \%$ \\
\hline Total & 50 & $100 \%$ \\
\hline Pesticide Used & & \\
\hline Using Pesticide & 4 & $8 \%$ \\
\hline Not Using Pesticide & 46 & $92 \%$ \\
\hline Total & 50 & $100 \%$ \\
\hline
\end{tabular}

\section{Coconut diseases and use of chemicals by farmers}

The data shown in Table 3 revealed that root wilt or "panunuyo ng palapa" was the most common disease devastating coconut trees in Dingalan as identified by 34 or
$68 \%$ of the respondents; the second most occurring diseases identified by 11 or $22 \%$ of the respondents was leaf spot; followed by bleeding identified by 4 or $8 \%$. Only one (1) or $2 \%$ identified bud rot as a disease.

Table.3: Summary Table for Coconut Diseases and Use Chemicals by Farmers

\begin{tabular}{|l|c|c|}
\hline \multicolumn{1}{c|}{ Coconut Diseases } & Frequency & Percentage \\
\hline Bleeding & 4 & $8 \%$ \\
\hline Bud Rot & 1 & $2 \%$ \\
\hline Leaf Spot & 11 & $22 \%$ \\
\hline Root Wilt & 34 & $68 \%$ \\
\hline Total Chemical Used & 50 & $100 \%$ \\
\hline \multicolumn{1}{|c|}{} & 49 & $98 \%$ \\
\hline No chemicals used & 0 & $0 \%$ \\
\hline Fungicide & 1 & $2 \%$ \\
\hline Insecticide & 50 & $100 \%$ \\
\hline Total & & \\
\hline
\end{tabular}

Despite the presence of the said diseases, almost all of the farmers (49 or 98\%) did not even use any chemicals. Only one (1) or $2 \%$ used insecticide to avert the disease. None of them used any fungicide at all.

It can be deduced from the data that coconut diseases abound, however no control was being undertaken by farmers to avert possible devastation of their crop which would hurt their future income. This further implies that they may not be aware of the consequences this may bring, or simply they may be needing an assistance from an agriculturist to address the problems.

\section{Fertilizer management of coconut farmers}

Table 4 shows the fertilizer management practices of the respondent coconut farmers. Management was described in terms of type of fertilizers used and frequency of application.

Table.4: Summary Table on Fertilizer Management Practices by the Coconut Farmers

\begin{tabular}{|l|c|c|}
\hline \multicolumn{1}{|c|}{ Fertilizer Used } & Frequency & Percentage \\
\hline Organic (salt) & 7 & $14 \%$ \\
\hline Inorganic Frequency of Fertilizer Application & 0 & $0 \%$ \\
\hline No Fertilizer Used & 43 & $86 \%$ \\
\hline Total & 50 & $100 \%$ \\
\hline \multicolumn{1}{|c|}{} & 3 & $6 \%$ \\
\hline Monthly & 0 & $0 \%$ \\
\hline Semi-Annual & 3 & $6 \%$ \\
\hline Quarterly & & \\
\hline
\end{tabular}




\begin{tabular}{|l|c|c|}
\hline Annually & 1 & $2 \%$ \\
\hline No Fertilizer Application & 43 & $86 \%$ \\
\hline Total & 50 & $100 \%$ \\
\hline
\end{tabular}

It can be viewed from the table that only seven (7) out of 50 respondents used fertilizer, specifically organic fertilizer in coconut farming. Of these seven (7) or $14 \%$, three (3) or $6 \%$ applied fertilizer monthly, another three (3) or $6 \%$ applied fertilizer quarterly and another applied fertilizer annually. It can also be noted that salt was used as fertilizer by the three (3) or $6 \%$ of the total number of farmer-respondents used organic fertilizer. Interview with the respondents revealed that two (2) of them used 20 to 30 $\mathrm{kg}$ of salt quarterly, while one (1) used 40 to 50 on a per year basis

The findings on fertilizer management practices of the respondents only verified the previous findings that they seemed to have no adequate know-how on coconut farming, other than the conventional use of salt as fertilizer. They were unaware that (inorganic) fertilizer was necessary in farming. It was also evident that they were aware on the frequency fertilizer application. It was evident that farmers need to be trained on the kind and frequency of fertilizer use to make their coconut farming sustainable.

\section{Coconut marketing practices in Dingalan Marketing Practices}

The marketing aspect of coconut farming is described in terms of the farmers' manner of marketing their product, pricing approach, and harvesting mode.

As can be gleaned from Table 5, the data on marketing method practiced by farmer-respondents show that majority of them use the farmer-harvester-retailer way of selling their product wherein upon harvest, it goes directly to the retailer without the involvement of any middle man. They price coconut on a per piece basis. The interview also revealed that coconut, primarily "buko" or young coconut are desired for its succulent meat and sweet juice, is sold from P6 during lean season to P13 during peak season. Summer and Christmas season were considered the peak seasons. Majority of the coconut farmers harvested and marketed their produce once a month. They sold at an average of 9 to 12 fruits per tree per month.

Table.5: Summary Table in terms of Marketing Practices

\begin{tabular}{|c|c|c|}
\hline Marketing Method (Buko/Matured Coconut) & Frequency & Percentage \\
\hline Farmer - middlemen - consumer & 3 & $6 \%$ \\
\hline Farmer - wholesaler - retailer - consumer & 1 & $2 \%$ \\
\hline Farmer - retailer - consumer & 2 & $4 \%$ \\
\hline Farmer - processor - consumer & 2 & $4 \%$ \\
\hline Farmer - end - user & 10 & $20 \%$ \\
\hline Farmer - harvester - retailer & 32 & $64 \%$ \\
\hline Total & 50 & $100 \%$ \\
\hline \multicolumn{3}{|l|}{ Pricing Approach (Buko/Matured Coconut) } \\
\hline Per kilogram & 0 & $0 \%$ \\
\hline Per piece (at an average of P8 per piece) & 50 & $100 \%$ \\
\hline Per bunch & 0 & 0 \\
\hline Total & 50 & $100 \%$ \\
\hline \multicolumn{3}{|l|}{ Frequency of Harvesting } \\
\hline Every 15 days & 1 & $2 \%$ \\
\hline Monthly & 46 & $92 \%$ \\
\hline Every 45 days & 3 & $6 \%$ \\
\hline Total & 50 & $100 \%$ \\
\hline
\end{tabular}

\section{The financial aspect of the coconut farming} industry in Dingalan

The financial aspect of coconut farming industry was described in terms of capital investment and income per harvest.
Table 6 shows that the respondents' capital investment on coconut farming from the time of planting the stock up to the point the trees are producing fruits which ranged from $\mathrm{P} 10,000$ to $\mathrm{P} 50,000$. 
Table.6: Capital Investment and Income per Harvest of Coconut Farmers

\begin{tabular}{|l|c|c|}
\hline Amount of Capital & Frequency & Percentage \\
\hline P 10,000 to P 20,000 & 21 & $42 \%$ \\
\hline P 21,000 to P 30,000 & 2 & $4 \%$ \\
\hline P 31,000 to P 40,000 & 0 & $0 \%$ \\
\hline P 41,000 to P 50,000 & 27 & $54 \%$ \\
\hline Total Mean = P 32,100 & & $100 \%$ \\
\hline \multicolumn{1}{|c|}{ Mean = P 3,880 } & 30 & \\
\hline P 1,000 to P 4,000 & 10 & $70 \%$ \\
\hline P 4,001 to P 7,000 & 2 & $20 \%$ \\
\hline P 7,001 to P10,000 & 3 & $4 \%$ \\
\hline P10,001 to P13,000 & 50 & $6 \%$ \\
\hline Total (Php) & & $100 \%$ \\
\hline
\end{tabular}

Considering that the capital investment of the farmers was only a one shot investment, the gain could be equated into monthly income. Note that earnings could be more than twice the investment. However, the average monthly income of $\mathrm{P} 3,880$ was low relative to the cost of living for a family with children who needed to be educated and fed. This was indicative of the difficulty the farmers were experiencing because of the meager income they get from coconut farming not even sufficient for their daily subsistence.

As reflected in the table, the income of farmers ranged from $\mathrm{P} 1,000$ to $\mathrm{P} 13,000$. However, a large majority of them (35 or $70 \%$ ) were earning only between P1,000 and $\mathrm{P} 4,000$; followed by 10 or $20 \%$ who were earning between $\mathrm{P} 4,001$ and $\mathrm{P} 7,000$. Only a few, comprising two (2) and three (3) or $4 \%$ and $6 \%$ were earning P7,001 to $\mathrm{P} 10,000$ and $\mathrm{P} 10,001$ to $\mathrm{P} 13,000$, respectively.

\section{Problems Encountered by Coconut Farmers}

The study revealed that the problems encountered by coconut farmers ranged from a number of factors that included climatic events, plant infestation and diseases, lack of coconut farming knowledge, and lack of support, among others. Enumerated below are the problems they identified:

1. Natural calamities like typhoon and bad weather.

2. Infestation of pest and attack of coconut leaf beetle, rhinoceros beetle, and rat.

3. Destruction of coconut trees due to coconut diseases like root wilt, leaf spot, bleeding and bud rot.

4. Lack of technical knowledge in production and technology for both farm owners and workers.
5. Lack of agricultural support from the government like providing farm inputs, calamity assistance and fertilizer subsidies.

6. Poor farm-to-market road.

7. Indiscriminate cutting of trees

8. Low yield, low return from coconut farming

9. Theft of coconut fruits

10. Low and fluctuating price of coconut products.

\section{Summary, Conclusions and Recommendations}

The following are the findings of the study:

1. The average size of coconut plantation of farmers was 1.68 hectares; majority of the farmers were growing 51 to 250 trees; and the average coconut yield per tree per year was 107.

2. In terms of farming practices, it was found out that although majority of the coconut trees were infested by coconut beetle, rat and rhinoceros beetle, only four (4) or $8 \%$ of the farmers were using insecticides. Even if coconuts were infected with bleeding, bud rot, leaf spot and root wilt, only one (1) or $2 \%$ was using insecticides.

In terms of fertilizer management, only seven (7) out of 50 farmers used fertilizers, and all of these seven used organic fertilizer (salt). Three (3) out of these seven (7) applied fertilizer monthly, another three (3) applied fertilizer quarterly or every three months and another applied fertilizer annually.

3. In terms of marketing practices, majority of the farmers were found to be selling their produce by way of farmer-harvester-retailer mode on a per piece basis. Majority of them harvested and marketed their produce monthly. 
4. The farmers spent an average of P32,100 as onetime capital investment in growing and maintaining their coconut farm. Out of this, they earned an average of $\mathrm{P} 3,880$ per harvest or an average of $\mathrm{P} 46,560$ per year.

5. The problems encountered in coconut farming included the following: natural calamities, infestation; diseases; lack of technical knowledge in farming; lack of agricultural support from the government; poor farm-tomarket road; indiscriminate cutting of trees; low yield; theft of coconut fruits, and low and fluctuating price of coconut products.

\section{CONCLUSIONS}

The following are the conclusions of the study:

1. Coconut farms in Dingalan was manageable in terms of size and number of trees, but the yield was low and needed improvement.

2. The farming practices of coconut farmers are too traditional that needs improvement.

3. The coconut farming industry has no systematic marketing system that would promote their product and enhance their pricing.

4. The coconut farming industry in Dingalan was not very profitable and did not help improve the condition of the farmers.

5. The problems encountered in coconut farming are due to technical, natural and social factors that can be addressed by strong policy measures.

\section{Recommendations}

Based on the findings and conclusions of the study the following are thus recommended:

1. Schools, particularly SUCs, must implement functional extension program to help the coconut farmers in Dingalan, to improve their farming capabilities.

2. The farmers must be provided with capability training to familiarize them with more effective farming system.

3. The farmers should be taught how to form a cooperative that will look into their marketing practices and value-adding their product and possible by-products.

4. Further study on how to improve the profitability of coconut farming must be conducted.

5. The LGU should support the industry by issuing industry-friendly issuances that would address even their problems on illegal coconut tree loggers and thieves.

\section{REFERENCES}

[1] Burton, J. (2018). The world leaders in coconut production.https://www.worldatlas.com/articles/theworld-leaders-in-coconut-production.html

[2] Ridgeway, S.(2018). Different Uses for a CoConut. https://owlcation.com/stem/Different-Uses-for-a-

Coconut

[3] Press Information Bureau (2018). Government of India, Ministry of Agriculture and Farmers Welfare http://pib.nic.in/newsite/PrintRelease.aspx?relid=1796 69

[4] Dar, Wiliam (2017) State of the PH coconut industry and what must be done

[5] Eyzaguirre, Pablo B. (2018) Farmers' contribution to improving the value and uses of coconut through the maintenance and use of genetic diversity

[6] Dingalan Ecoprofile, 2007

[7] Tena,Vergil (2016) Coconut (Cocos Nucifera) Farming System in Dingalan, Aurora, A Thesis

[8] Kumar, R.(2005). Research Methodology- A Step-byStep Guide for Beginners, (2 ${ }^{\text {nd }}$. Ed.) Singapore, Pearson Education. Retrieved from: http://www.ihmetan.edu/PDF/notes/Research Method ology.pdf. Date Accessed: February 17,2014.

[9] Subia,G.,Mones, E.and Alfonso, A.(2018). Existing and Preferred Organizational Culture at Wesleyan University - Philippines. International Journal of Management and Commerce Innovations. ISSN 23487585, Vol.5, Issue 2, pp: (796-801). 